\title{
GHENT UNIVERSITY'S INTERDISCIPLINARY SSH-CONSORTIA - A STRATEGY TO ENHANCE THE SOCIETAL IMPACT OF RESEARCH
}

NOËL KLIMA, STEFAN MEYSMAN, JULIE CARLIER, ALEXIS DEWAELE AND ESTHER DE SMET DOI: 10.22163/fteval.2019.381

\section{INTRODUCTION}

$\mathrm{G}$ hent University is one of the biggest Universities in Belgium with 11 faculties, 117 departments and 650 research institutes containing around 9000 employees and 41.000 students (Ghent University, 2016). Ranked best Belgian University on 61 in the Shanghai ranking in 2018 Ghent University is home to 17 highly cited authors and more than 55 grantees since the start of the European Research Council (ERC) funding scheme. In such a large organisation, Ghent University considers the potential for top-down steering of research strategy limited. Therefore, Ghent University applies a range of decentralised research strategy initiatives including SSH-focused ones.

Due to a national and regional focus on "objective" distribution of research funds and a willingness to become a world-renowned knowledge economy, performance indicators are often limited to quantitative and individual output and traditional figures such as number of publications, PhD's and citations. When compared to the STEMM (Science, Technology, Engineering, Mathematics and Medicines) disciplines, this system is widely known to disadvantage the Social Sciences and Humanities (SSH) in part because of a different research and publication culture. In measuring performance, traditionally less attention is given to indicators such as (interdisciplinary) cooperation or service to society while many SSH disciplines show especially here a strong potential and some already well-developed good practices. In addition, characteristics such as a high level of individuality of researchers, less "big" funding due to smaller research groups as well as a high teaching load and lack of (planned) societal value creation in SSH, urged Ghent University's Research Department to support joint initiatives in SSH to strengthen research excellency and impact through the stimulation of cooperation.

One of these initiatives entailed the set-up of interdisciplinary SSH research consortia. The SSH research consortia may be considered the counterpart of Ghent University's business development centers as funded by the "Industrial Research Fund" (IOF)' which were installed to bridge the gap between strategic fundamental research, industrial cooperation and technological innovation. The SSH-consortia are complementary to these STEMM initiatives and have the purpose to bridge the gap between SSH (fundamental) research, interdisciplinary cooperation and societal impact.

\section{PILOT PHASE OF THEMATIC SSH-CONSORTIA}

Within the framework of a new research policy in 2012 (DOZA, 2012a), Ghent University launched a competitive call for consortia to strategically support several SSH disciplines. A pilot funding of five years was granted to five consortia including a strengthening of the middle management through a coordinator on a postdoctoral level. All five consortia received a "carte blanche" to develop the consortium and to define and focus on specific priorities within broader missions of interdisciplinarity, internationalisation, academic excellence and societal value creation. It was important in this initiative that the consortia could start to operate from scratch and develop their own aims, mission, and eventually output. The five consortia were funded through the university internal "Special Research Fund" (BOF) and hosted at different faculties.

\section{“CRIME, CRIMINOLOGY AND CRIMINAL POLICY" (CCCP)}

At the Faculty of Law and Criminology the consortium "Crime, Criminology and Criminal Policy"2 has been installed. The consortium deals with the domain of deviance and its (policy) response, as well as in the areas of crime and security. The consortium brings together 16 scholars from different disciplines in six departments working inter-disciplinary on security, crime and deviance related topics in local, national, European and international contexts. The range of topics covers e.g. research into vulnerable groups in detention, policing and police mobility, desistance from crime and drug use, (youth) crime prevention, but also other complex cross-border phenomena such as cybercrime, terrorism and organised crime, or privacy, information exchange, big data, law enforcement responses, policies and laws. The consortium fosters knowledge translation and exchange, strengthening societal value creation leading to societal impact and stimulates synergies and cooperation with external academic, policy and practice partners from different disciplines. 


\section{PIRENNE CONSORTIUM FOR MEDIEVAL STUDIES}

The Pirenne Consortium for Medieval Studies ${ }^{3}$, primarily based at the Faculty of Arts and Philosophy fosters cross-disciplinary research into the medieval period and advances knowledge exchange between these different fields of study, as well as with societal partners and the general public. The consortium brings together all medievalists at Ghent University under the promotor-board of 29 senior scholars. It draws more than 100 members from four faculties and ten departments, covering both Science, Technology, Engineering and Mathematics (STEM) and SSH. Research on original medieval heritage such as texts, images, maps, artefacts and sites is the core business, including the development and integration of "Digital Humanities" methods. However, the consortium also houses expertise in collaboration with archives, libraries, museums, and other cultural heritage institutions, as well as with several societal sectors such as education, policy and tourism.

\section{GHENT CENTRE FOR GLOBAL STUDIES}

The Ghent Centre for Global Studies ${ }^{4}$ is hosted at the Faculty of Political and Social Sciences. As an interdisciplinary research platform it unites scholars from Social and Economic Geography; International, EU and Conflict and Development Studies; Economics, Sociology, Global History and Ethics; Human Rights Law and Intercultural Pedagogy. With a total of 11 research groups from six different faculties the consortium focuses on the critical study of globalisation, with special attention to the interaction of global and local processes. With its interdisciplinary research and education - on urbanisation, rural transformations, economic governance and migration - the Centre aims to contribute to the societal debate on, and evidence-based policy-making and development cooperation for, sustainable development.

\section{"WORKING TOGETHER FOR MENTAL HEALTH" - PSYNC}

"Working Together for Mental Health" - PSYNC 5 refers to "psychology' and 'synchronise". This research consortium is housed within the Faculty of Psychology and Educational Sciences. Its objective is to develop a common strategy to translate clinically relevant research to the clinical field and to the broader society. The consortium is dedicated to improving the mental health of all citizens, running research projects in close collaboration with diverse stakeholder groups, with a clear focus on generating real world impact and providing societal innovation. PSYNC's main goals are reaching vulnerable groups, stressing the importance of lifecycle perspective on mental health, increasing mental health literacy and health promotion, safeguarding ethical perspectives, and developing innovations in the treatment of mental health disorders.

\section{“INNOVATION AND ALL INCLUSIVE GROWTH" - CIG}

The consortium "Innovation and All Inclusive Growth" - CIG6 found its base at the Faculty Economics and Business Administration. The consortium's goal is to act as an economic and scientific base for everything which concerns innovation, entrepreneurship and all-inclusive growth at Ghent University. Research focuses on different topics from different angles such as technological innovation and entrepreneurship, "Corporate Social Responsibility" (CSR), corporate and entrepreneurial finance, business architecture and modelling, innovation and growth at macro level. This consortium decided not to continue its work after the pilot phase and therefore was not part of some of the later mentioned evaluation mechanisms after the five year pilot phase.

All consortia have created their own strategic plan and modus operandi, and developed their own support structure in line with their thematic focus and their members who are researchers from different faculties and departments. The consortia and how they operated have been evaluated on different occasions and from different angles. Before it was decided to provide continued funding, four out of five consortia were evaluated on three criteria that were discipline-specific, consortiumspecific and coordinator-specific.

\section{EXTERNAL PEER EVALUATION (DISCIPLINE-SPECIFIC)}

In 2016, the consortia received a first evaluation through an external discipline-specific peer review evaluation coordinated by the Ghent University Research Department in collaboration with the faculties of Arts and Philosophy, Faculty of Law and Criminology, Faculty of Economics and Business Administration, Faculty of Psychology and Educational Sciences and the Faculty of Political and Social Sciences. This evaluation was not consortium specific but rather discipline specific. However, the consortia have been considered being part of the respective faculties which also received the attention of the evaluators. The consortia and their role have been evaluated as valuable parts of the relevant faculties and disciplines. The focus on interdisciplinary cooperation was considered an asset in the faculty structures.

\section{STAKEHOLDER PEER EVALUATION (CONSORTIUM- SPECIFIC)}

In 2017, a new targeted call was launched for the continuation of the five pilot consortia. For this evaluation the panel consisted of members not only from the University Research Council, but also of individuals from non-academic stakeholder groups. External members came from the public sector, civil society and international organisations. All consortia have been evaluated in a two-fold manner. First, each consortium was considered retrospectively by evaluating the outputs and outcomes with regard to the former "Ghent University Research Policy Plan" (2012 
- 2016) under which the consortia were installed (DOZA, 2012). Second, the consortia were assessed from a future-oriented perspective. The panel looked into the ambition, the organisation, the strategy of the consortium and its match with the current "Ghent University Research Policy Plan" (DOZA, 2017).

As a result, the decision was made to continue funding for four of the five consortia and structurally embed the role of the research coordinator as a shared position with a long-term contract. The major strengths of the four were the stimulation of interdisciplinary research in each thematic area but also the stimulation on a cross-consortium level such as e.g. joint events, projects, knowledge exchange which was considered a major added value for the research and impact agenda. Also, the involvement of the coordinators in several central University research policy working groups was a positive outcome of the organic bottom-up development of the consortia during the pilot period.

As a consequence, the objective was to build on the developed strengths and particularities of each consortium and the naturally grown cooperation between them through knowledge sharing and research policy involvement. With a consolidation of the existing consortia new opportunities with regard to interdisciplinarity7 and societal value creation8 leading to societal impact would be created. The consortia will be evaluated every five years on their organisation and management, their interdisciplinarity through cooperation and joint initiatives, their societal impact through impact case studies and the planning of the future five year period.

\section{INTERNAL EVALUATION (COORDINATOR-SPECIFIC)}

During the pilot phase, the coordinators in some of the consortia changed due to staff turnover. After the decision to fund the existing consortia permanently, the acting coordinators have been evaluated separately by a Ghent University panel including members from the consortia, the Research Department and the Ghent University Research Council. This evaluation examined the coordinator's profile, approach and strategy to manage the consortium for the next five years. The panel gave positive advice to extend their contracts towards indefinite appointments. All four coordinators could show the relevant thematic expertise and management skills to coordinate the consortia on a permanent basis. All have also built up a close collaborative relationship with various policy officers within the Research Department and strengthened the information flow and the cooperation between the central university level and the consortium researchers from the different departments. The profile, skills and approaches of the coordinators will also be used to define the requirements for the recruitment of future coordinators for additional consortia.

\section{CONSORTIA ARE EMBEDDED IN THE BIGGER RESEARCH POLICY AGENDA}

The SSH-consortia are embedded in the general research policy and were also part of Ghent University's policy initiative focusing on the ex- cellence in the humanities, social and behavioural sciences. This specific initiative brought together different incentives which were targeted specifically at the faculties Law and Criminology, Arts and Philosophy, Psychology and Educational Sciences, and Political and Social Sciences and was intended to strengthen research quality and research strategy, taking into account the idiosyncrasies of research in these fields (DOZA, 2012b). Ghent University's intention to enhance research excellence through higher research quality, visibility and recognition accompanies the initiated SSH initiatives. Next to the SSH consortia, budgets were reserved for additional professor and tenure track positions and a reform of the sabbatical rules (DOZA, 2012b). From other research policy initiatives, such as the "research spearheads", also known as the MRP initiative ("Multidisciplinary Research Partnerships") (DOZA, 2010), Ghent University learned about the demand to develop methods and incentives relevant for SSH with regard to the bibliometric bias, the high individuality of researchers and less "big" funding due to smaller groups as well as the high teaching load and the lack of (focused) societal value creation. At the same time, a new policy plan on societal value creation called "IM-pact" was developed by the Research Department wherein the SSH-consortia and their structural embedment plays one of the key roles to stimulate interdisciplinary cooperation and enhance societal value creation of research (DOZA, 2015).

The experiences from the pilot led Ghent University to consider the SSH-consortia as a good practice and led to a wish to expand the initiative across the university. The focus, the working and the development of the four SSH-consortia are considered to be an inspiration for other new interdisciplinary consortia working in other research areas. Ghent University intends to extend the initiative with six more consortia to strengthen its general profile with regard to interdisciplinarity and societal impact.

\section{CONSORTIUM COORDINATOR WITH A PERMANENT ASSIGNMENT}

The structural embedment and long term vision requires the sustainable position of the coordinator. Against common university customs fixed term assignments would in this case weaken the position of the coordinator and hamper the working and development of the consortium. Interdisciplinary cooperation and societal impact creation take time and require consolidated and sustainable relationships both with and between researchers and non-academic stakeholders. To limit the risk of a high fluctuation of staff and related loss of expertise, Ghent University decided to provide fixed contracts for the coordinators.

The coordinators are knowledge brokers who promote collaboration and networking within the consortium, between the consortia and with the Research Department. They develop expertise in facilitating, promoting and appreciating interdisciplinarity and take initiatives to support internal interdisciplinary cooperation. Within and across the consortia and in collaboration with the Research Department the coordinators elaborate generic and thematic initiatives and share knowledge with regard to research policy, interdisciplinarity and social impact.

The coordinators are also monitoring the sustainability and long-term strategy of the consortium and optimise the involvement and commitment of the researchers in the consortium. The coordinators assist the 
researchers during the idea phase for acquiring external financing. They follow and influence the European research policy, both generically and thematically for the consortium and for Ghent University.

The coordinators also manage societal value creation and societal impact activities. Therefore, they develop expertise in a number of value creation and impact related topics relevant to the consortium. As antennae, the coordinators are in contact with several stakeholders playing an active role in the expansion of the stakeholder network of the consortium, e.g. by setting up a structural advisory board of societal stakeholders. Finally, the coordinators develop and use models for the design of value creation and impact processes and for the evaluation of impact, in line with their research expertise.

Each of the coordinators has generic expertise within the research areas of the consortium at PhD level and is able to assess strategically the potential of projects and other initiatives with respect to scientific and societal impact. They are knowledge brokers, provide technical assistance and safeguard the pathways to impact, defined by each of the consortia. The coordinators receive an annual lump-sum bench fee that can be used to support their work agenda and where coordinators themselves act as budget holders.

\section{JOINT CONSORTIA PATHWAYS TO IMPACT - AN EXTRA DIMENSION}

The work of a coordinator in the thematic consortium makes around $70-80 \%$ of the total workload. The other $20-30 \%$ are dedicated in crossconsortium activities and generic Ghent University work. Besides the interdisciplinarity within each of the consortia the collaboration between the coordinators and with the central Research Department brings an extra dimension. Within this extra dimension of interdisciplinarity, impact, relevant outputs and outcomes as well as knowledge and information exchange could be generated. This concerns university-wide initiatives in function of knowledge sharing, expertise building and training cooperation with the Research Department and other Ghent University partners in the area of interdisciplinarity, societal value creation, impact and research policy, including prospecting funding opportunities and promotion of best practices.

All coordinators are members of the "Impact Task Force" and the Alpha-EU working group at central University level, participate in writing of position papers ${ }^{9}$ (e.g. Ghent University, 2017a; 2017b; 2018), organise joint workshops ${ }^{10}$, information sessions ${ }^{11}$, lectures ${ }^{12}$, participate in joint projects ${ }^{13}$ and plan to organise an interdisciplinary impact award. All joint activities generate outputs feeding the common objectives to increase the societal impact of Ghent University SSH research. Also, it adds to the optimisation of the impact research policy and evaluation at Ghent University and to the defence of Ghent University's interests at European level e.g. through input on the development of EU Framework Programmes. This exchange on Ghent University's (EU) research policy is highly valued by all involved actors and shows already a range of tangible results.

\section{LESSONS LEARNED}

The pilot experiment of the SSH-consortia brought a range of positive experiences to the surface but also points of potential improvement in the future. The SSH-consortia were established in an environment where interdisciplinarity and openness for other disciplines is necessary, but not self-evident. The structural support for researchers in view of interdisciplinary collaboration showed positive effects. The coordinators stimulate researchers towards more cooperation and collaboration within their consortia but also with external parties. The organisation of interdisciplinarity requires good leadership by the coordinators but also from the professors and researchers involved. The different consortium pilot tracks showed that just a coordinator in a group of researchers is not sufficient to gain effects from a consortium. Dedication and commitment is required from coordinators and the professors and researchers to be able to reach another level of cooperation.

An important step in the process was the decision to make the coordinator position fixed term and extract them from the "usual" academic career track of a research oriented postdoc. Some of the consortia lost their coordinators during the pilot phase and even one consortium stepped out during the pilot phase. Some researchers left for a fixed term position elsewhere or followed their regular research track on top of their consortium management duties. A safe position with an autonomous budget from the start prevents a high level of fluctuation among the coordinators, which goes along with a loss of the acquired expertise. This kind of initiative should not just be a "stepping stone" for postdocs on their jump to the next project contract or the next step on their way towards a professorship. Nevertheless, teaching and research activities can be of added value to stay in touch with academic expertise, and to disseminate the coordinator's expertise on interdisciplinarity and impact related topics. The profile of the consortium coordinators requires expertise in research and topic knowledge, but in addition (research) management and policy expertise and expertise on societal value creation and research funding. This position is different from a pure research position and should be filled with people motivated to build the relevant expertise as a pivot point between research, research policy, funding, outreach and management.

In addition, a well organised research information system is required in each consortium but also on central level to avoid the loss of information and knowledge. Information management and data exchange still depended very much on individual researchers. Therefore, incentives are needed for participating researchers to value their engagement and commitment within a consortium might help to convince researchers much quicker to dedicate more effort and energy in interdisciplinary cooperation and societal value creation of their research. This could be done e.g. through including open science incentives in their personal career goals.

It will take time until the results from interdisciplinary collaboration develop effect. The five-year period has shown that this is a process of building trust, dedication and commitment. This needs also to be created and maintained between coordinators, researchers and central university research policy departments. An interaction on regular basis in structural working groups raises the tonus of joint actions between the three parties. Mutual recognition and understanding is important to fruitfully bring together the different working levels.

Starting with a pilot on a small scale has proven to be the right way. The learning effect from the pilot evaluations puts the Research Depart- 
ment in a position to immediately call for permanent consortia building on the structures and cooperation grown during the pilot phase.

A strong asset in the process has been the bottom-up approach in the development of the structure and working of the consortia. The researchers do not consider the consortia an extra institution with heavy administrative burden which operates independent from the other existing structures such as research institutes, departments or faculties. The bottom-up approach made it possible to fully adapt the consortia to the needs of the researchers and to build a complementary structure that is intertwined with all other structures. A fully functioning consortium brings assets to the central research policy level of the University.

The boon or bane of the bottom-up approach was the diversity of the consortia and their working which is difficulty to measure and compare according to strict and measurable indicators. Ghent University has chosen for panels to evaluate the work individually. Clear guidelines on how the consortia will be evaluated periodically are necessary. Ghent University decided to focus on four domains: the organisation of the consortium and internal procedures, the interdisciplinarity of the working, impact case studies and the future planning.

The SSH-consortia were inspired and considered complementary to the "Industrial Research Funds" (IOF) business development centres that were established over a decade ago. However the bonds and cooperation between both initiatives are developing very slowly. The same applies for the exchange and cooperation with the University technology transfer office which was not fully exploited during the pilot phase. In the case of Ghent University's pilot bottom-up approach, an exchange with STEMM disciplines was in some cases existent based on single projects or individual collaboration moments. This might be taken away for the next cohort of interdisciplinary consortia at Ghent University but also for Universities that want to start with such an initiative. It is certainly recommended to engage immediately and structurally with STEMM researchers that do have relevant connection with the topic. In some cases this is not possible or relevant. However, it will help to open silo researching and opens borders for new cooperation ventures.

\section{FUTURE PERSPECTIVES OF THE SSH-CONSORTIA}

The four SSH-consortia will continue on permanent basis embedded in the research policy structure of Ghent University. In some consortia (where relevant) exchange and cooperation with STEMM researchers will be further stimulated and extended especially with regard to the next "European Framework Programme Horizon Europe". The consortia will work through a range of specific pathways to impact and also a range of joint ones. The initiatives will inter alia cover the enhancement of impact literacy among researchers and informing research policy at Ghent University level and EU level. A new call will make the number of consortia grow from four to ten which also will lead to new challenges. The cooperation and exchange infrastructure built during the pilot phase provides a situation where new consortia with their new coordinators are able to be immediately integrated. Finally, the consortia and the Research Department will continue to exchange knowledge on impact measurement.

\section{REFERENCES}

DOZA (2010). Strategisch Speerpuntenbeleid Onderzoek. Ghent: Ghent University. [eng. Strategic Spearheads Policy Research]

DOZA (2012a). Ghent University - Research Policy Plan 2012 - 2016. Ghent: Ghent University.

DOZA (2012b). Een hefboom naar excellentie in de humane, sociale en gedrags- wetenschappen. Ghent: Ghent University. [eng. A lever for excellence in the human, social and behavioral sciences]

DOZA (2015). Strategisch project maatschappelijke valorisatie van onderzoek - IM-pact. Ghent: Ghent University. [eng. Strategic project societal value creation of research - IM-pact]

DOZA (2017). Ghent University - Research Policy Plan 2017 - 2021. Ghent: Ghent University.

Ghent University (2016). Focus on Ghent University. Retrieved September 10, 2018 from: http://unigentdemo.online-magazine.nl/en/magazine/11623/815119/focus_on_ghent_university-_cover.html.

Ghent University (2017a). Societal impact of SSH research: perspectives on co-creation and working with societal readiness levels. Retrieved September 15, 2018 from: https://www.ugent.be/en/research/positionpapers

Ghent University (2017b). Position Paper IE H2020 The 'SSH embedding Challenge'. Retrieved September 15, 2018 from: https://www.ugent.be/ en/research/position-papers.

Ghent University (2018). Call on the European Union to create highquality dedicated and embedded SSH research opportunities in FP9. Retrieved September 15, 2018 from: https://www.ugent.be/en/research/ position-papers.

\section{AUTHORS}




\section{NOËL KLIMA}

IDC Crime, Criminology and Criminal Policy, Ghent University

Universiteitstraat 4, Ghent, 9000 (Belgium)

E: noel.klima@ugent.be

\section{STEFAN MEYSMAN}

IDC Pirenne Consortium for Medieval Studies, Ghent University

Sint-Pietersnieuwstraat 35, Ghent, 9000 (Belgium)

E: stefan.meysman@ugent.be

\section{JULIE CARLIER}

IDC Ghent Centre for Global Studies, Ghent University

Universiteitstraat 8, Ghent, 9000 (Belgium)

E: julie.carlier@ugent.be

\section{ALEXIS DEWAELE}

IDC PSYNC - Working Together for Mental Health, Ghent University

Henri Dunantlaan 2, Ghent, 9000 (Belgium)

E: alexis.dewaele@ugent.be

\section{AND ESTHER DE SMET}

Research Department, Ghent University

Sint-Pietersnieuwstraat 25, Ghent, 9000 (Belgium)

E: esther.desmet@ugent.be

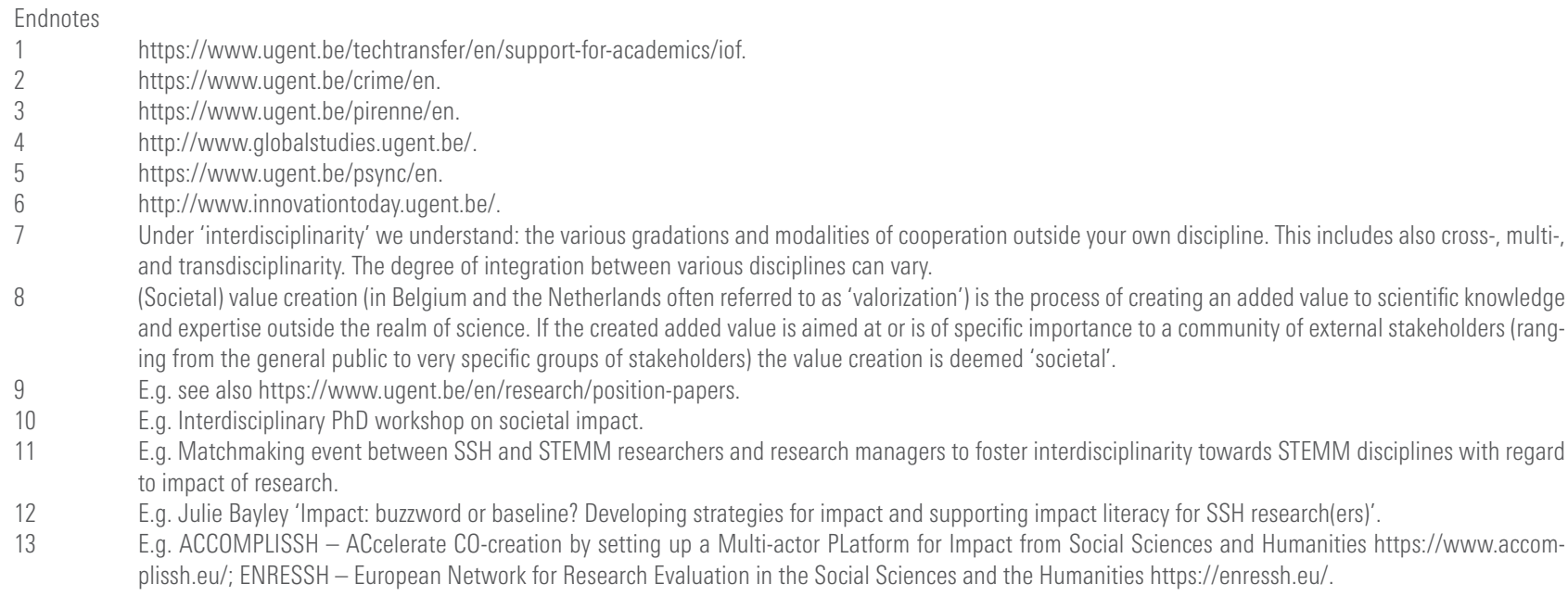

$7 \quad$ Under 'interdisciplinarity' we understand: the various gradations and modalities of cooperation outside your own discipline. This includes also cross-, multi-, and transdisciplinarity. The degree of integration between various disciplines can vary.

8 (Societal) value creation (in Belgium and the Netherlands often referred to as 'valorization') is the process of creating an added value to scientific knowledge and expertise outside the realm of science. If the created added value is aimed at or is of specific importance to a community of external stakeholders (ranging from the general public to very specific groups of stakeholders) the value creation is deemed 'societal'.

$9 \quad$ E.g. see also https://www.ugent.be/en/research/position-papers.

$10 \quad$ E.g. Interdisciplinary PhD workshop on societal impact.

11 E.g. Matchmaking event between SSH and STEMM researchers and research managers to foster interdisciplinarity towards STEMM disciplines with regard to impact of research.

12 E.g. Julie Bayley 'Impact: buzzword or baseline? Developing strategies for impact and supporting impact literacy for SSH research(ers)'.

13 E.g. ACCOMPLISSH - ACcelerate CO-creation by setting up a Multi-actor PLatform for Impact from Social Sciences and Humanities https://www.accomplissh.eu/; ENRESSH - European Network for Research Evaluation in the Social Sciences and the Humanities https://enressh.eu/. 